\title{
Exploration on the Classified Training Mode of International Economics and Trade Talents
}

\author{
Lingyan Meng \\ Department of Economics and Management \\ Jining University \\ Qufu, Shandong, China, 273115 \\ mly7312@163.com
}

\begin{abstract}
The classified training of talents is the objective requirement of diversified social demands and individualized development in colleges. This paper adopted the literature analysis, case research, experience research and comparative analysis to discuss the necessity and urgency of classified training, define its targets and types, and explain its connotation in the major of International Economics and Trade. In addition, the author explored the implementation plans from the perspective of teaching objectives, course systems, teaching methods and quality assessment, namely, the three-team constructions, three teaching reforms and three combinations could be used as the foundation, path and guarantee for classified training so as to promote its implementation and promotion in the related major of national colleges and innovate the related talent training mode.
\end{abstract}

Keywords-training mode; higher education; international economy; innovation and entrepreneurship; team construction

\section{INTRODUCTION}

In the era of higher education being accessible to the mass, college students have more differences in the cultural foundation, learning ability, interest and employment choice, and they are more likely to be independent and individual. However, the field has put forward increasing demands for talents, colleges existing the single training mode, and the unequal demand and supply of talents being more serious, all of which have laid a foundation for the transition of the talent training mode from the single to the classified. The exploration with classified training mode has been a significant project in our national college education, which can enrich the popularity of higher education, and provide real paths and important references for the great promotion of college students.

The connotation of classified training mode can be generalized as employment guidance, ability-oriented and classified training. Based on the personal employment choice and ability as well as social demands, talent training can be implemented in the direction of academic research, trade practice and being cross-discipline and comprehensive. It should be launched from the two lines of "what kind of talents" and "how to train"[1]. With the support of systematic and progressive course system, it emphasizes the individual and different development of training objectives, and treats the modern diversified teaching methods, scientific management system and various quality assessment systems as the implementation paths. Classified training is the inheritance, tolerance and innovation with original training mode, which highlights the independence and individualized development requirements of students and the diversified demands of society on talents. It aims at strengthening students' learning motivation, ability to choose a career and potential for sustainable development.

\section{TARGETS OF CLASSIFIED TRAINING IN THE MAJOR OF INTERNATIONAL ECONOMICS AND TRADE}

\section{A. Training academic research talents}

The training of academic research talents should be based on the "knowing the fundamental theories", which requires students to have a solid knowledge of professional theories have initial working abilities to work in the related areas. These can help them receive higher education and finally achieve academic talent training. The training plan should highlight the following two aspects: the first one is that the course system setting should be distinctly theoretical and advanced. The course content is more professional and profound, and its knowledge composition should be further developed to train students' economics rational thinking, make them have solid theories and stronger academic research abilities. Meanwhile, it should reflect the major achievements and advanced results, various ideology schools and academic viewpoints and future development direction of the subject in the field, which can provide solid theoretical basis for further study and theoretical innovation. The other one is that teaching method highlights the case and task driving. The characteristic of such kind of talents is to finish learning tasks with the exploration, and its teaching objective will no longer be pure knowledge imparting and extension of general knowledge, but strengthening the scientific and research ability. In the class teaching, the teaching method of target guidance, problem research and task driving should be emphasized.

\section{B. Training the practice-oriented talents of economics and trade}

International Economics and Trade, as the practical economics, is rather political, social and practical[3]. The training objective can be described as that student should systematically master the basic theories, be familiar with international rules and procedures of economics and trade, have correct recognition with the operation system and 
development principles of current international economics and trade, and skillfully use the technology of information communication and foreign language. They can realize crosscountry and cross-culture communication and be competent in practical work and foreign work in international trade. Two aspects should be focus on. The first one is to emphasize the obtaining of qualification certificate. Such examination is not only the entrance permit of employment but the significant tool to increase the success rate of employment. In the training process, the training of certification examination should be emphasized. And the test content and type should be highlighted in daily teaching so as to make more students pass it. The other one is that teaching part should highlight the training and practice of practical ability. It is necessary to standardize the practical teaching content, highlight the construction of learning and practicing, strengthen the integration of industry and teaching, improve the system of practical teaching, complete the teaching materials for practice, promote the effect of practical teaching and strengthen students' practical ability by means of case teaching, software simulation practice and situation simulation.

\section{Training cross-discipline and comprehensive talents}

The training objective can be described as mastering the theoretical knowledge of economy, management, e-commerce, foreign language and computer, having a wide knowledge of humanities and social science, and having good ability of communication, coordination and team cooperation, as well as innovative thoughts and entrepreneurial spirit. In addition, they can afford the task of management, practical business, research and publicizing and planning in government agencies and other units. There are two points needing emphasizing: the first one is the development and design of cross-discipline comprehensive course. Talent training plans can be reformed to adjust course system and teaching content, guide students' optional choice and minoring the second major, and realize the training of cross-discipline and comprehensive talents. Such talents can have professional knowledge at a certain field on the basis of generally mastering the related knowledge. For instance, the field of law, metallurgy or other emerging ones. As a result, the disciplinary crossing can be realized to form certain employment advantage. The second one is innovative and entrepreneurial training. It includes innovative training, entrepreneurship training and practice. The first one means that teachers and students jointly establish a team in which students are guided to independently finish the design, research condition preparation, project implementation, research reports writing and result (academic) communication. In the second one, each student plays one or more roles in the implementation, doing the work of formulating commercial plans, launching feasible research, simulating enterprise operation, participating in enterprise practice, and writing entrepreneurship reports. In the final one, under the joint guidance of professional teachers and enterprise teachers, students' team can acquire the capital and support in the incubating base of innovation and entrepreneurship for the result of previous innovation training projects(or innovative experiment), which can help transform the result and launch entrepreneurial practice.

\section{DEEPEN THREE REFORMS--THE METHODS OF}

REALIZING THE CLASSIFIED TRAINING OBJECTIVES

The classified training can be implemented from the reform of course system, practical teaching, teaching methods and assessment system. All of these can satisfy the different demands of the educated who can master professional theories, promote their applied and practical abilities, and lay a solid foundation for future work featuring cross-industry, crossdiscipline, and cross-area.

\section{A. The reform of course system}

Teaching system should be oriented with the promotion of employment ability, and treat the industry demand as the significant measuring index of course system and teaching methods reform as well as material construction. And the four modules should be adjusted and improved, including professional basic course, core course, elective course and quality development course. The practical teaching system should be corresponding with the professional training objectives to strengthen the training of students' practical ability. In addition, the innovation and entrepreneurial training plan for college students should be formulated, and the course aiming at innovating thoughts and methods, and related with entrepreneurship training like project management, enterprise management and venture investment should be launched to provide experimental fields, policy support and other facilitating conditions for students participating in the project.

\section{B. The reform of practical teaching}

The training of practical ability can be regarded as the theme to create the professional practical teaching network featuring the combination of colleges and enterprises, on-line and off-line, academic education and training, as well as being overall, comprehensive and dimensional. It highlights the training of practical ability and guarantees students' strong skills, obvious employment advantages and sustainable development [4]. Firstly, it should be done that the adjustment and improvement of the practical teaching plan, the construction of supporting materials and college practical base, as well as the platform construction of comprehensive practical software like POCIB. Secondly, academic education and professional ability should be strengthened so as to make college students more competent. Thirdly, practice base outside the college should be greatly expanded, and the deep cooperation and win-win mode should be explored by positively attempting to jointly construct practice rooms and experimental resource base, jointly publishing the textbooks and applying for scientific topics[5].

\section{The reform of teaching methods and quality assessment}

It is of great necessity to strengthen teaching research, do various teaching reform, improve teaching management and control, and establish diversified quality assessment system with the center of classified training objectives so as to guarantee the realization of diversified training objectives. Firstly, the teaching concept of enlightenment can be used as the guidance, and the main teaching methods include exploring cases, situation simulation and task driving. Secondly, we should strengthen the construction of network teaching 
resource, regard the information technology as the carrier, and fully use on-line courses and professional teaching websites to strengthen the construction of practice and case base as well as on-line courses, and achieve the publishing of electronic materials. The third one is the diversification of quality assessment system. The course quality and content and individualized demands among students should be connected to explore diversified quality assessment system. For example, in the part of graduate paper and internship, the mode of academic papers, research reports and entrepreneurial plans can be regarded as test content. And corresponding assessment system should be established.

\section{STRENGTHEN THREE TEAM CONSTRUCTIONS--THE SUPPORTING OF CLASSIFIED TRAINING OBJECTIVES}

The construction of teachers' team should be based on the current status to promote the level and optimize the structure. Three team constructions should be highlighted so as to promote the entire power of teaching staff and the major, which can provide significant support for the realization of classified training objectives.

\section{A. The construction of scientific and research team}

Based on the vertical and horizontal topics, it is necessary to give full play to the backbone of scientific research, do the construction of scientific and research team, and form the joint force in project declaration and finishing. The current basis can be depended on so as to further certify research direction, strengthen the academic workshop discussion and communication inside and outside the school, encourage teachers to positively participate in various social work organized by government, society and field associations, enrich their practical work experience and expand the influence of the major and team.

\section{B. The construction of entrepreneurship mentor team}

Teachers are encouraged to strengthen the research of entrepreneurial knowledge and theories, practice teaching staff and promote the guidance level of innovation and entrepreneurship on the basis of college students' innovation and entrepreneurship plans and professional skills competitions organized by the Ministry of Education and Students' Union. Such method can strengthen students' entrepreneurial spirit, innovative thoughts and training of entrepreneurial skills, and promote the entire level of innovative education in this major from the two aspects of teachers' levels and students' abilities.

\section{Strengthen the construction of excellent teaching team}

There are two significant supports in the construction of teaching staff. The first one is that the basis should include teaching and research projects, teaching reform, teaching construction, the competition between the man and woman. The second one is that a teaching staff featuring strong teaching skills, abundant practical experiences, and higher practical level on the basis of the integration of professional experimental rooms and the combination of enterprises and colleges. Specifically, the team and course construction can be launched by constructing the core teaching group of
International Trade, International Trade Affairs and International Finance and seizing the opportunity of declaring the on-line exquisite video class at the level of school, province and country. Secondly, the opportunity of the competition for young teachers and innovation and entrepreneurship should be seized to motivate the enthusiasm of professional young teachers, train teaching staff, find out excellent talents, train teaching backbones and strengthen the power and advantages of the team. Thirdly, strengthen the international communication and cooperation. Professional teachers have an access to having further study abroad so that they can master the advanced dynamics of disciplinary development. And foreign experts will be invited to give the lecture and make communication in our college. Finally, teachers can be selected to train themselves in enterprises and incubation base of college entrepreneurship, and acquire the identification of double teachers by learning. In addition, experts and backbones in the field of foreign trade will be positively employed as the part-time teachers.

\section{THREE COMBINATIONS--THE STRONG GUARANTEE FOR CLASSIFIED TRAINING OBJECTIVES}

The selection of teaching modes is vital to the classified training. The teaching mode of "combining colleges and enterprises, inside and outside the class, academic education and training" can obviously promote the cooperation between enterprises and colleges, expand classroom teaching, and make students have better understanding with knowledge theories These combinations are of great significance to the classified training.

\section{A. The combination of colleges and enterprises}

The cooperation channels between colleges and enterprises should be broadened to provide the platform for teachers' research, practical teaching and students' innovation and entrepreneurship. Specific work and measures include the following aspects: firstly, promote the combination of production and teaching, broaden the resource of innovation and research funds, hire experts and backbones of enterprises and associations into the classroom, and jointly finish daily teaching, graduate internship and paper guidance; secondly, the cooperation mechanism should be innovated so that teachers can participate in the management and practice of enterprises, and the talent training and win-win development can be reached by jointly declaring topics and strengthening the cooperation between colleges and enterprises; thirdly, strengthen the expansion and construction of students' internship and practice base, provide convenience for students to work at the related enterprises, create conditions for the simulated training, and help students truly experience the real demands of the field and enterprise on talents.

\section{B. The integration of inside and outside class}

The second classroom can be created to attract more students to have training opportunities with various modes and content, and it can be established by the graduate guidance center, entrepreneurship training center, qualification examination and training center. The innovation and entrepreneurship training class for college students can be 
established to train students' self-training, innovative awareness and ideological abilities. It includes the two groups of scientific research training and entrepreneurship training for college students, which includes the discipline competition studio, entrepreneurship project studio, and research training studio. The whole process should be treated strictly, from the topic selection, investigation and research, literature exploration, data analysis, the writing of research reports to the project conclusion. And those students who have strong scientific and innovative ability can be accepted into teachers' research topics so as to help students have the preliminary ability of project survey, market analysis and customer communication and management.

\section{The combination of academic education and training}

The academic education and professional ability should be treated equally to strengthen the training of preparing the postgraduate, civil servant and vocational qualification, and highlight the orientation of employment. Teachers are supposed to construct a guiding group, office for promoting the employment and association for a professional career. At the same time of scientifically designing the content, procedures and assessment modes in the teaching plan, students should be guided to participate in the professional qualification exams of being a merchandiser, customs officer, customs inspector, document clerk, or export clerk. The special fund can be founded to give support and rewarding to those students who got the vocational qualification and the mode of being guided by experts and integrated with social force to jointly running a school should be adopted to implement the policy of free tutoring and employment incentives. As a result, the competitiveness of graduated in employment can be strengthened.

\section{CONCLUSION}

Classified training is oriented with students' individualized and independent development, which caters to the popularity trend of higher education, satisfies the diversified and different demands of the field with talents, featuring scientific and objective. It is of great significance to guiding the talent training that being oriented with occasional development and social demands, and centered with the promotion of employment ability, and regarding training diversified and versatile talents as the real task. The deepening of course system, practicing of teaching system and reform of assessment methods can be treated as the paths. And strengthening the teaching, scientific research and innovation and entrepreneurship can be regarded as significant support. In addition, the combination of enterprises and colleges, inside and outside class, academic education and training can be viewed as a strong guarantee for realizing the targets of classified training. Such a series of measures are featuring integrated, comprehensive, systematic, operative, practical and having wide objectives. Besides, it can enrich the current research results in this area, provide major references for promoting talent training quality, and have far-reaching effects on promoting the talent training system.

\section{REFERENCES}

[1] Liu Yan. Exploration on the training mode of "stratified teaching, triage training and classified talents" in engineering colleges $[\mathrm{J}]$. China University Teaching, 2018(08) (In Chinese)

[2] Yang Suhong. The present situation and strategies of stratified and classified cultivation of higher science talents[J]. China University Teaching, 2015(08) (In Chinese)

[3] Xu Jie. Exploration on the transformation and development of local colleges and universities to promote the construction of high-level application-oriented colleges and universities[J]. China Higher Education Research, 2016(12) (In Chinese)

[4] Zhou Yingjia. Deepen the reform of talent training model under the guidance of social needs[J]. China Higher Education Research, 2014(04) (In Chinese)

[5] Peng Xiaoxia. Innovation and practice of full-time master of engineering training system--a case study of Beijing University of Aeronautics and Astronautics[J]. Academic Degrees \& Graduate Education, 2013(2) (In Chinese) 